\begin{tabular}{ll}
\hline & $\begin{array}{l}\text { Kastamonu Eğitim Dergisi } \\
\text { Kastamonu Education Journal }\end{array}$ \\
$\begin{array}{l}\text { Eylül 2019 Cilt:27 Sayı:6 } \\
\text { kefdergi.kastamonu.edu.tr }\end{array}$ & Başuru Tarihi/Received: 01.10 .2018 \\
Kabul Tarihi/Accepted: 14.02 .2019 \\
Dol: $10.24106 /$ kefdergi.3371
\end{tabular}

\title{
Tek Başına Olmayı Tercih Etme Ölçeği: Türkçe Formunun Geçerlik ve Güvenirlik Çalışması ${ }^{1}$
}

\section{Preference for Solitude Scale: Validity and Reliability Study of the Turkish Form}

\section{Öz}

\author{
Tunahan ERPAY², Gökhan ATiK ${ }^{3}$
}

Bu çalışmada, Burger (1995) tarafindan geliştirilmiş olan Tek Başına Olmayı Tercih Etme Ölçeğinin Türkçeye çevrilmesi ve üniversite öğrencilerinden elde edilen veri setlerinin geçerlik ve güvenirliğinin araştrılması amaçlanmıştır. Ölçeğin geçerlik ve güvenirlik çalışmaları iki farklı katılımcı grup üzerinde yürütülmüştür. lllk grup 245 (\%24.1 erkek, \%75.9 kadın), ikinci grup 470 (\%30.2 erkek, \%69.8 kadın) üniversite öğrencisinden oluşmaktadır. íki katılımcı grubu üzerinde gerçekleştirilen doğrulayıcı faktör analizi sonuçlarına göre, ölçeğin Türkçe Formu orijinal ölçek çalışmasında olduğu gibi 12 maddeden ve tek faktörden oluşmaktadır. Gerçekleştirilen güvenirlik çalışmalarına göre ise, ölçeğin Türkçe Formu kabul edilebilir düzeylerde iç-tutarlık katsayılarına ve testi yarılama güvenirlik değerine sahiptir.

Anahtar Kelimeler: tek başına olma, ölçek uyarlama, geçerlik, güvenirlik

\section{Abstract}

In this study, it was aimed to translate Preference for Solitude Scale developed by Burger (1995) into Turkish and to investigate validity and reliability of the data collected from university students. The validity and reliability studies of the scale was carried out on two different participant groups. The first group was composed of 245 (24.1\% male and $75.9 \%$ female) and the second group was consisted of 470 (30.2\% male and $69.8 \%$ female) university students. The results of confirmatory factor analyses in two separate studies showed that the Turkish Form of the scale was composed of 12 items and one dimension as in the original form. According to the reliability studies performed, the Turkish Form of the scale has acceptable internal consistency coefficients and split-half reliability.

Keywords: solitude, scale adaptation, validity, reliability

1. Bu çalışma birinci yazarın yüksek lisans tezi verilerine dayalı olup, ikinci yazar birinci yazarın danışmanlığını yapmıştır. Ayrıca bu çalışma, $9-11$ Mayıs 2018 tarihleri arasında Manisa'da düzenlenen 8. Uluslararası Eğitimde Araştırmalar Kongresi'nde sözlü bildiri olarak sunulmuştur.

2. Ankara Üniversitesi, Eğitim Bilimleri Fakültesi, Ankara, Türkiye; https://orcid.org/0000-0003-2662-464X

3. Ankara Üniversitesi, Eğitim Bilimleri Fakültesi, Ankara, Türkiye; http://orcid.org/0000-0001-5386-6770

Atıf / Citation: Erpay, T. \& Atik, G. (2019). Tek başına olmayı tercih etme ölçeği: türkçe formunun geçerlik ve güvenirlik çalışması. Kastamonu Education Journal, 27(6), 2493-2500. doi:10.24106/kefdergi.3371 


\section{Extended Abstract}

Purpose and Significance: Solitude is the basic and inevitable experience of human life. No matter who people are with, they always keep this basic solitude state in their nature. Because of our way of being, people face with this uniqueness and solitude (Costache, 2013). Knafo (2012) defines the solitude, which has various definitions in the literature, as the state of being physically and psychologically separate from the others due to the free will of the person or compulsory reasons. Solitude refers to a situation which is different from loneliness (Burger, 1995; Long \& Averill, 2003). One of the important aspects of solitude is that it pleasures and develops individual in different ways, allows one to illuminate himself and to increase his creativity (Hollenhorst \& Jones, 2001; Long \& Averill, 2003; Long, Seburn, Averill, \& More, 2003; Storr, 1988). Moreover, solitude is an effective condition for increasing the feelings of freedom and peace, meeting the needs of relaxation and recreation (Wang, 2006). In the case of solitude without the feeling of need for social interaction as in loneliness, people enjoy being with themselves and renew their inner worlds before social interaction (Burger, 1995; Rokach, 2011). In addition to such benefits, solitude which includes little amount of negative aspects has attracted the attention of the researchers (Long et al., 2003). It is an important question which level of experience of solitude can be healthy in general for the individuals. At this point, the only scale that measures the degree of solitude for adults and university students is Burger's (1995) Preference for Solitude Scale. The scale was used as a data collection tool in many studies in the literature (e.g. Driskell, Salas, \& Hughes, 2010; Hills \& Argyl, 2001). In Turkey, the lack of a measurement tool to determine the extent of solitude which preferred by individuals was considered as a problem statement. Therefore, the purpose of this study was to translate the scale mentioned here into Turkish and to study the validity and reliability of the data gathered from university students through Turkish version of the scale.

Method: The adaptation study of the scale was carried out on two different groups of participants studying at a state university in Ankara, Turkey. The first participant group consisted of 245 ( $24.1 \%$ male, $75.9 \%$ female) and the second participant group composed of 470 (30.2\% male, 69.8 female) undergraduate students. The language adaptation of the scale was performed as the first stage of the adaptation process, and then whether one-factor structure of the original scale is valid for the data obtained through Turkish form of the scale was also examined with confirmatory factor analyses (CFAs). Since the data obtained were categorical data, CFAs were performed using the robust weighted least squares (WLS) estimation method on the polychoric correlation matrix and asymptotic covariance matrix. The internal consistency coefficients of the scale were calculated by Kuder-Richardson 20 method. These procedures were performed for both data sets. The test-retest reliability coefficients were also calculated as an evidence of reliability.

Results: The fit indices obtained from the CFA result for the first measurement were as follows: $\chi^{2}$ was 89.76 ( $p$ $=.001$ ) and the degree of freedom (sd) was 54. $\chi^{2} / s d$ ratio 1.66 (criterion < 3; Kline, 1998), RMSEA (mean square root of approximate errors) .05 (criterion < .05; Browne \& Cudeck, 1993), SRMR (standardized root mean square residual) .08 (criteria $\leq .08 ; \mathrm{Hu} \&$ Bentler, 1999), TLI (Tucker-Lewis index) .99 (criterion $\geq .95 ;$ Hu \& Bentler, 1999), and CFI (comparative fit index) .99 (criterion $\geq .95 ; \mathrm{Hu} \&$ Bentler, 1999). According to these results, it was seen that the general fit indices of one factor model were at acceptable levels. The internal consistency reliability coefficient was calculated as .83 for the entire scale. The CFA results for the second measurement are as follows: $\chi^{2}$ value was $141.24(p=.000)$ and the degree of freedom $(s d)$ was 54 . The ratio of $\chi^{2} / s d$ was 2.62 , RMSEA .06, SRMR .08, TLI .98 , and CFI .98. These indices indicated that one factor structure of the scale was also valid for the data of second participant group. For the second measurement, the internal consistency coefficient for the entire scale was .77 . The test-retest reliability of the scale was examined with a two-week interval on 37 participants and it was found to be $.81(p<.01)$.

Conclusion and Discussion: The results of the CFAs revealed that one factor structure for the original form of the scale was also valid for the Turkish version of the scale. In addition, the internal consistency reliability coefficients and test-retest reliability coefficient showed that the scale had an adequate reliability. As a result, the Turkish form of the scale could be used for determining the level of solitude of university students in Turkey. In this way, the relationship between solitude and loneliness which is related to solitude but has different aspects from solitude can be investigated more extensively in Turkey. Also through this scale, the relationship between solitude and various factors can be examined in the context of Turkey. The scale can also expand and differentiate the wholesale perspective on loneliness in psychology and counseling fields in Turkey. Researchers can understand the importance of solitude by means of this scale and give more place in research than loneliness which investigated mostly (Long and Averill, 2003). 


\section{Giriş}

Tek başına olma (solitude) kavramının alanyazında birçok tanımı mevcuttur. Burger (1995) tek başına olmayı, sosyal etkileşimden kaçınma olarak ifade ederken, Knafo (2012) ise tek başına olmayı bireyin seçimi ya da istenmeyen koşullar sonucu oluşmuş, diğerlerinden fiziksel ve psikolojik olarak geri çekilme, kendi başına olma hali olarak tanımlamaktadır. Tek başına olma kavramının alanyazında kendine yer bulması 1940'lı ve 1950'li yıllarda başlamış (Fromm, 1941; Winnicot, 1958, 1965), daha sonrasında çeşitli kuramcılar ve bilim insanları çalışmalarında artan şekilde kavrama yer vermeye başlamıştır (Larson \& Chikszentmihayli, 1978; Maslow, 1970). Psychınfo veri tabanındaki 2000 yılına kadar makaleler tarandığında yalnızlık (loneliness) kavramıyla ilgili 1937 makaleye ulaşılabilirken, tek başına olmayla (solitude) ilgili sadece 184 makaleye erişilebilmektedir (Long, 2000). Bununla birlikte kavramla ilgili çalışmalar 1900'lü yılların sonlarında ve 2000'li yılların başında daha da artmış (Burger, 1995; Cramer \& Lake, 1998; Galanaki, 2004; Wang, 2006), ekoloji (Bruneau, 2011), felsefe (Costach, 2013), psikoloji (Long \& Averill, 2003) ve teoloji (Barbour, 2014) gibi farklı bilim dallarında çalışmalar ortaya konulmuştur. Tek başına olma ile ilgili yapılan çalışmaların bazılarında kavramının doğası kuramsal açıdan incelenirken (Costach, 2013; Long \& Averill, 2003), bazı çalışmalarda tek başına olma ile ilişkili çeşitli değişkenler ele alınmıştı (Burger, 1995; Long, Seburn, Averill, \& More, 2003). Son dönemde ise, tek başına olmanın eğitim ortamlarında kullanımına değinen çalışmalara rastlanmaktadır (Chan, 2016; Stern, 2016).

Alanyazında çoğu araştırmacı sosyal ilişkileri araştırmaya istekli ve yönelimli olsa da, bir kısım araştırmacının ilgisini bireylerin mahremiyeti konusu çekmektedir. İnsanların mahremiyeti yaşaması acılı bir yaşantıdan, mutluluk verici bir duruma kadar değişkenlik göstermektedir. Kimi insanlar daha fazla şekilde mutluluğu ve olumlu duyguları bu mahremiyet anlarında seçmektedir. Bu anlara tek başına olma anları denmektedir ve her insan farklı derecelerde bu yaşantiyı tercih etmektedir (Burger, 1995).

Tek başına olma durumu bireylere farklı açılardan yararlar ve firsatlar sunmaktadır. Nitekim tarihin her döneminde birçok yazar, din insanı ve sanatçı tek başına olmanın sağladığı katkılardan yararlanmıştr. $\mathrm{Hz}$. Musa, $\mathrm{Hz}$. İsa ve $\mathrm{Hz}$. Muhammed gibi peygamberler tek başına geçirdikleri zamanlarda keşfettiklerini daha sonra halklarıyla paylaşmışlardır (Long \& Averill, 2003). Thoreau, Dickinson ve Kafka gibi yazarlar da kendilerinin yaratıcılık süreçlerinde tek başına geçirdikleri zamanın rolünü vurgulamışlardır. Aslında, tek başına olma kavramından önemli bir sosyal fenomen olarak da bahsedilebilir. Çünkü tek başına olma sürecinde elde edilen spiritüel, sanatsal, dini veya insani yaratıcı kazanımlar ve olgunlaşmalar sosyal hayatın akışını ve şeklini önemli oranda etkilemektedir (Long, 2000; Long \& Averill, 2003).

Araştırmacılar tek başına olma kavramından yararlanabilmeyi kişinin sosyal çevresinin yokluğuna dayanabilme derecesiyle ilişkili görmektedir (Larson, 1990; Winnicot, 1958). Winnicot’a göre $(1958 ; 1965)$ belirli yaşa gelmiş bebek arttk annesinden ayrılarak belli aralıklarla tek başına olmayı deneyimlemelidir. Bu çocuğun ilerideki yaşamında tek başına olmanın faydalarından yararlanabilmesi ve kendi kendine yetebilmesi adına önemli bir gelişimsel görevdir.

Tek başına olma kavramının kişiye sağladığı faydalarına alanyazında değinilmiştir. Burger (1995) tek başına olma zamanlarında kişilerin kişisel problemlerini ve kararlarını sağlıklı bir şekilde ele alabileceklerini, gelecekteki sosyal ilişkileri için kendisini hazırlayabileceğini iddia etmiştir. Larson (1990) tek başına olma aracılığıyla insanların öz değerlendirme, duygusal yenilenme ve konsantre olabilme düzeylerini artırabileceklerini belirmiştir. Storr (1988) ise tek başına olmanın yaratıcılığı ve kendini keşfetme becerisini artırdığını belirtmektedir. Kavramın ortaya konulan faydalarını daha sistematik belirlemek amacıyla Long (2000) tek başına olmayı iki boyuta (pozitif ve negatif) ayırmıştır ve kişiler tarafindan pozitif boyutun daha çok tecrübe edildiğini bulmuştur. Daha sonrasında da, tek başına olma Long ve arkadaşları (2003) tarafindan dokuz boyuta (yaratıcılık, problem çözme, eğlence, yalnızlık, yakınlık, spiritüellik, kendini keşfetme, iç huzur, kendini gizleme), Wang (2006) tarafindan ise yirmi boyuta (problem çözme, kendini keşfetme, aydınlanma, yaratıcılık duygusal düzenleme, yalnızlık, can sıkıntısı, yabancılaşma, özgürlük, hayal kurma, iç huzur, rahatlama, vakit geçirme, kendini zenginleştirme anımsama, yakınlık, aşkınlık, uyum, duygusal farkındalığı yükseltme ve özlem) ayrılmıştır. Bu tek başına olma türlerinde dikkati çeken nokta genel olarak tek başına olmanın olumlu boyutlardan oluşmasıdır.

Nance ve Mays (2013) çalışmalarına katılan her bireyin tek başına olmanın belli düzeyini stresten arınma, aydınlanma ve ortalama zihinsel sağlık için gerekli gördüğünü belirtmiştir. Çok fazla ya da az değil, yeterli ve orta düzeyde tek başına olmanın üretkenlik, problem çözme ve görevleri yerine getirmede de etkili olduğu ifade edilmiştir. Burger (1995) de çalışmasında bireylerin orta düzeyde tek başına olmayı tercih ettiklerini bulmuştur.

Bireylerin tek başına olmayı tercih etme düzeyleri birbirinden farklııık göstermektedir. Alanyazında bu farklılığı ve tek başına olma eğilimini yetişkinlerde ölçen tek ölçme aracı Burger (1995) tarafindan geliştirilen "Tek Başına Olmayı Tercih Etme Ölçeği"dir. Birçok ülkede, bireylerin tek başına olma eğilimlerini değerlendirmek için bu ölçme aracının uyarlandığı ve veri toplama aracı olarak kullanıldığı görülmektedir. Örneğin; Çin (Liang \& Leung, 2018; Wang, 2006), Hollanda (Staak, 2016) ve Brezilya (Testa, Rohde, \& Luciano, 2011) gibi ülkelerde ölçeğin uyarlama çalıșmaları yapılmıștır. Ayrıca, 
bu ölçme aracı, alanyazındaki birçok çalışmada da veri toplama aracı olarak kullanılmıştır (Cady, 2010; Driskell, Salas, \& Hughes, 2010; Hills \& Argyle, 2001; Long, 2000). Bir ölçme aracının farklı kültürlere uyarlanıp, o kültürlerde veri toplama aracı olarak kullanılıyor olması, elde edilen araştırma sonuçlarının uluslararası düzeyde karşılaştıııabilmesine de olanak tanımaktadır.

Tek başına olma kavramı bazı durumlarda yalnızlık kavramı ile karıştırılabilmektedir. Ancak tek başına olma durumunun yalnızlıktan farklı ve daha olumlu bir yapıyı belirttiği alanyazındaki çalışmalarda belirtilmektedir (Burger, 1995; Long \& Averill, 2003; Rokach, 2011). Yalnızlık durumunda yaşanan sosyal ilişki ihtiyacı ve bu ihtiyacın bireyde sebep olduğu olumsuz duygular (Perıman \& Peplau, 1981) tek başına olma durumunda görülmemektedir. Bu açıdan, tek başına olma ve yalnızlık kavramlarının ayrıştırılabilmesi ve doğru ölçümü için bu yapılar farklı ölçme araçları ile değerlendirilmektedir. Türkiye'de ve yurt dışında yalnızlığın değerlendirilmesinde sıklıkla kullanılan ölçme aracı UCLA Yalnızlık Ölçeği'dir. Russell, Peplau ve Ferguson (1978) tarafindan geliştirilen, daha sonra Russell, Peplau ve Cutrona (1980) tarafindan tekrardan revize edilen UCLA Yalnız Ölçeği kişilerin ne düzeyde yalnız olduklarını belirlemek amacıyla geliştirilmiştir. Bu çalışmada uyarlanan Tek Başına Olmayı Tercih Etme Ölçeği ise yalnızlıktan farklı bir yapı olan tek başına olmanın bireyler tarafindan ne düzeyde tercih edildiğini ortaya koymaktadır (Burger, 1995). Türkiye'de ise tek başına olma kavramının ölçülmesine dair bir ölçme aracı bulunmamaktadır ve bu bir intiyaç olarak göze çarpmaktadır. Bu ihtiyaçtan hareketle, bu çalışmada, Burger (1995) tarafindan geliştirilen bu ölçeğin Türkçeye çevrilmesi, ölçeğin Türkçe Formu ile üniversite öğrencilerinden elde edilen veri setinin geçerliğinin ve güvenirliğinin incelenmesi amaçlanmıştır.

\section{Yöntem}

\section{Katilımcılar}

Ölçeğin Türkçe Formunun geçerlik ve güvenirlik çalışmaları iki farklı katlııcı gruptan elde edilen veriler üzerinde yapılmıştır. Birinci katılımcı gruptaki 245 kişinin 59'u (\%24.1) erkek, 186'sı (\%75.9) kadındır. Katılımcılar Ankara'daki merkez bir üniversitede okuyan öğrenciler arasından uygun örnekleme yöntemi kullanılarak seçilmiştir. Katılımcıların yaş aralığı 17 ile 33 arasındadır (Ort. = 20.12, Ss = 1.97). Sınıf düzeyi bakımından, katılımcıların 72'si birinci sınıf $(\% 29.4)$, 55’i (\%22.4) ikinci sınıf, 37’si (\%15.1) üçüncü sınıf ve 81'i (\%33.1) dördüncü sınıf öğrencisidir.

Çalışmanın ikinci katılımcı grubu ise, uygun örnekleme yöntemi ile seçilen üniversite öğrencilerinden oluşmaktadır. Katılımcılar Ankara'nın merkez bir üniversitesinde eğitimlerine devam etmektedirler. Bu katılımcı grubunda yer alan 470 kişiden 142'si (\%30.2) erkek, 328'i (\%69.8) kadındır. Katılımcıların yaşları 18 ile 32 arasında farklılık göstermektedir (Ort. = 21.2, Ss = 1.90). Sınıf düzeyi bakımından, katlımcıların 88'i (\%18.7) birinci sınıf, 103'ü (\%21.9) ikinci sınıf, 133'ü (\%28.3) üçüncü sınıf ve 146’sı (\%31.1) dördüncü sınıf öğrencisidir. Bu çalışmada geçerlik ve güvenirlik çalışmalarının iki farklı grup üzerinde yapılma gerekçesi, birinci gruptan elde edilen veri seti üzerinde yapılan geçerlik ve güvenirliğin, farklı bir gruptan elde edilen veri seti için de geçerli olup olmadığı test etmek içindir.

\section{Veri Toplama Araçları}

Kişisel Bilgi Formu. Araştırmacılar tarafindan geliştirilen Kişisel Bilgi Formu ile katlımcıların cinsiyet, yaş ve sınıf düzeylerine ilişkin bilgiler elde edilmiştir.

Tek Başına Olmayı Tercih Etme Ölçeği (TBOTEÖ). Üniversite öğrencilerine yönelik geliştirilen ölçek, bireylerin ne derece tek başına olmayı tercih ettiklerini ya da tek başına olmaya ne derece eğilimli olduklarını ölçmeyi amaçlamaktadır. Ölçeğin orijinal formu 12 maddeden ve tek faktörden oluşmaktadır. Maddelerin her birinde iki seçenek bulunmaktadır. Seçeneklerden birisi tek başına olma durumunu ifade ederken (örn. "Kendi başıma olmaktan hoşlanırım"), diğeri tersi bir durumu (örn. "Insanlarla birlikte olmaktan hoşlanırım") ifade etmektedir ve katılımcılardan iki seçenekten birisini seçmesi istenmektedir. Ölçekten alınan puanlar 0 ile 12 arasında değişmektedir. Ölçekten alınan puanların yüksek olması, tek başına olmanın daha yüksek düzeyde tercih edildiğinin göstergesidir. Ölçeğin iç-tutarlık güvenirlik katsayıları Kuder Richardson 20 tekniği ile hesaplanmış ve iki farklı grupta .73 ve .70 değerleri elde edilmiştir. Ölçeğin test-tekrar test güvenirlik katsayısı ise .72 olarak bulunmuştur (Burger, 1995).

TBOTEÖ’nün uyarlama çalışmasında belirli bir süreç izlenmiştir. İlk adım olarak, ölçeği Türkçeye çevirmek ve geçerlik ve güvenirlik çalışmalarını yürütmek için Prof. Dr. Jerry M. Burger'den izin alınmıştır. Alınan izin sonrasında ölçek Türkçe ve İngilizceye hâkim ve alan uzmanı üç doktora öğrencisi ve bir öğretim üyesi tarafindan Türkçeye çevrilmiştir. Sonrasında, araştırmacılar tarafindan çeviri ifadeler incelenmiş ve en uygun ifadelerde karar kılınmışttr. Çeviri ifadeler, İngilizce karşılıkları ile birlikte alandaki üç öğretim üyesine gönderilmiş ve çevirilerin aslını yansıtma derecesi bakımından görüşleri alınmıştr. Bu görüşler doğrultusunda ölçeğin Türkçe Formu tekrar revize edilmiş ve son hali verilmiştir. Ölçeğin çeviri formunun son halinde orijinal ölçekte yer alan 12 madde yer almaktadır. 


\section{Veri Toplama Süreci}

Araştırmanın yürütülebilmesi için ilk olarak araştırmacıların görev yaptıkları üniversitenin Etik Kurulundan araştırma izni alınmıştır. Etik Kurul izni alınmasının ardından araştırmacılar ilk uygulama için görev yaptıkları üniversitenin çeşitli fakültelerinde ders vermekte olan öğretim elemanlarıyla irtibat kurup, bu kişileri araştırma hakkında bilgilendirmiş ve veri toplamak için uygun gün ve dersler tespit edilmiştir. Daha sonrasında araştırmacılar tarafindan belirlenen saatlerde belirlenen derslere girilerek öğrenciler araştırma hakkında bilgilendirilmiş (araştırmanın amacı, bilgilendirilmiş onam, gizlilik, gönüllülük) ve destekleri istenmiştir. İkinci uygulama çalışmasında da, araştırmacılar görev yaptıkları üniversitenin ilk katılımcı grubundan farklı olarak diğer fakültelerdeki öğretim elemanlarıyla irtibat kurmuş ve ilk aşamada belirtilen sürecin aynısı gerçekleştirilmiştir. Veri toplama sürecinde katılımcılardan kişisel bilgileri istenmemiştir. Veriler 2016-2017 Eğitim ve Öğretim Yılı Güz döneminde toplanmıştır. Uygulamalar yaklaşık olarak 15 dakika sürmüştür.

\section{Verilerin Çözümlenmesi}

Ölçeğin orijinal formunun faktör yapısının ölçeğin Türkçe Formu için de geçerli olup olmadığını ortaya koymak için doğrulayıcı faktör analizi (DFA) yapıımıştır. Bu çalışmada, doğrulayıcı faktör analizi belli gerekçelerden dolayı seçilmiştir. Alanyazında, açımlayıcı ve doğrulayııı faktör analizi olmak üzere iki tür faktör analizi bulunmaktadır (Tabachnick \& Fidell, 2013). Açımlayıcı faktör analizinde, birbirleri ile ilişkili değişkenlerin bir araya toplanarak tanımlanması ve özetlenmesi amaçlanmaktadır. Açımlayııı faktör analizi genel olarak ölçek geliştirme sürecinde, değişkenleri bir araya getirmek ve altta yatan süreçlerle ilgili hipotezler oluşturmak için kullanılmaktadır. Doğrulayıcı faktör analizi ise gizil süreçlerle ilgili bir kuramı test etmek için araştırma sürecinin ileri aşamalarında kullanılan çok daha karmaşık bir tekniktir. Bu açıdan, açımlayıcı faktör analizi kuram geliştirme ile ilişkiliyken, doğrulayıcı faktör analizi ise bir kuram testinin yapılması ile ilişkilidir (Tabachnick \& Fidell, 2013). Bu çalışmada da, tek başına olma durumu Burger (1995) tarafindan ortaya konulmuş ve test edilmiş bir yapıdır. Bu yapının başka kültürlerde elde edilen veri setleri için geçerli olup olmadığı test etmek için açımlayıcı faktör analizi yerine özellikle doğrulayıcı faktör analizi kullanılmıştır. Tek Başına Olmayı Tercih Etme Ölçeği'ne ait tek faktörlü yapı iki farklı grup verisi üzerinde DFA ile test edilmiştir. Doğrulayıcı faktör analizleri LISREL 8.71 istatistik programı (Joreskog \& Sorbom, 2004) aracılı̆̆ıla gerçekleştirilmiştir. Doğrulayıcı faktör analizleri öncesinde, yapılması gereken istatistiksel varsayımlar (uç değerler, eksik değerler gibi) (Ullman, 2001) incelenmiştir. Uç ve eksik değerler varsayımlarının testleri için IBM SPSS 22 istatistik programından yararlanılmıştır. Uç değer analizinde, her iki veri setin için de +3.29 ve -3.29 değerleri aşan (Tabachnick \& Fidell, 2013) herhangi bir standardize edilmiş z puanına rastlanmamıştır. Her katılımcı gruptan elde edilen veri setindeki bazı değişkenlerdeki eksik değer oranının \%1'in altında olduğu tespit edilmiş ve bundan dolayı herhangi bir eksik değer atama yöntemi kullanılmamıştr. Doğrulayıcı faktör analizleri, elde edilen veriler kategorik veri olduğu için polikorik korelasyon matrisi (polychoric correlation matrix) ve asimptotik kovaryans matrisi (asymptotic covariance matrix) üzerinden ağırlıklandırılmış en küçük kareler (robust weighted least squares [WLS]) tahmin yöntemi kullanılarak yapılmıştr. Ölçeğin Türkçe Formuna ilişkin güvenirlik katsayıları ise Kuder Richardson 20 tekniği ve testi yarılama güvenirliği ile IBM SPSS 22 istatistik programı kullanılarak hesaplanmıştr.

\section{Bulgular}

Tek Başına Olmayı Tercih Etme Ölçeğinin Türkçe Formuna ilişkin geçerlik ve güvenirlik bulguları aşağıda sunulmuştur.

\section{TBOTEÖ’nün Türkçe Formunun Geçerlik Çalışmalarına İlişkin Bulgular}

Birinci uygulamadaki veriler üzerinde yapılan DFA sonuçlarına göre elde edilen uyum katsayıları şöyledir: $\chi^{2}$ değeri $89.76(\mathrm{p}=.001)$, serbestlik derecesi $(\mathrm{sd})$ ise $54^{\prime}$ tür. $\chi^{2} / \mathrm{sd}$ oranı 1.66 (kriter <3; Kline, 1998), RMSEA (yaklaşık hataların ortalama karekökü) değeri .05 (kriter <.05; Browne \& Cudeck, 1993), SRMR (standardize edilmiş kök ortalama kare ar-

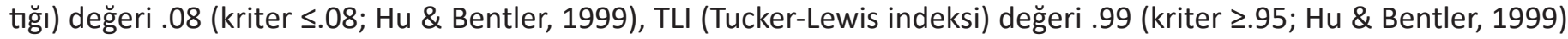
ve CFI (karşılaştırmalı uyum indeksi) değeri ise .99'dur (kriter $\geq .95$; Hu \& Bentler, 1999). Bu sonuçlara göre, birinci uygulama verilerine dayalı olarak, tek faktörlü modele ilişkin genel uyum katsayılarının kabul edilebilir düzeylerde olduğu görülmektedir. Genel uyum katsayılarının yanı sıra, DFA ile elde edilen parametre değerleri Tablo 1'de verilmiştir. Tablo 1'e göre, faktör yükleri .34 ile 88 arasında, R2 değerleri ise .12 ile .78 arasında değişmektedir.

Tablo 1. Tek Başına Olmayı Tercih Etme Ölçeği Türkçe Formunun Standardize Edilmiş Parametre Tahminleri-Birinci Uygulama

\begin{tabular}{ccccc}
\hline Maddeler & Standardize Edilmiş Faktör Yükleri & $\mathbf{S H}$ & $\mathbf{t}$ & $\mathbf{R}^{\mathbf{2}}$ \\
\hline Madde 1 & .83 & .05 & 18.46 & .70 \\
Madde 2 & .61 & .08 & 8.06 & .37 \\
Madde 3 & .64 & .07 & 9.27 & .41 \\
Madde 4 & .71 & .06 & 12.30 & .51
\end{tabular}




\begin{tabular}{ccccc}
\hline Maddeler & Standardize Edilmiş Faktör Yükleri & $\mathbf{S H}$ & $\mathbf{t}$ & $\mathbf{R}^{\mathbf{2}}$ \\
\hline Madde 5 & .60 & .07 & 8.62 & .36 \\
Madde 6 & .88 & .04 & 25.17 & .78 \\
Madde 7 & .53 & .08 & 7.08 & .28 \\
Madde 8 & .65 & .07 & 10.04 & .42 \\
Madde 9 & .34 & .08 & 4.21 & .12 \\
Madde 10 & .86 & .04 & 19.48 & .74 \\
Madde 11 & .75 & .05 & 14.37 & .56 \\
Madde 12 & .85 & .04 & 20.25 & .72 \\
\hline
\end{tabular}

Not. Tüm t değerleri manidardır $(p<.001)$.

íkinci uygulamada elde edilen DFA sonuçlarına göre; $\chi^{2}$ değeri $141.24(p=.000)$, serbestlik derecesi (sd) ise 54'tür. $\chi^{2} / s d$ oranı 2.62 (kriter <3; Kline, 1998), RMSEA değeri .06 (kriter <.07; Hair, Black, Babin, \& Anderson, 2010), SRMR

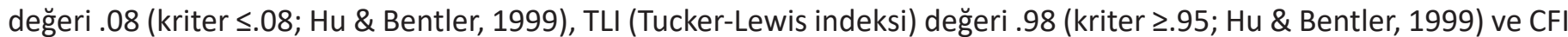
değeri ise .98'dir (kriter z.95; Hu \& Bentler, 1999). Elde edilen katsayılar, ölçeğin tek faktörlü yapısının ikinci uygulama verisi için de geçerli olduğuna işaret etmektedir. DFA sonucunda elde edilen parametre değerleri Tablo 2'de verilmiştir. Tabloya göre, faktör yükleri .22 ile 84 arasında, $R^{2}$ değerleri ise .05 ile .71 arasında değişmektedir.

Tablo 2. Tek Başına Olmayı Tercih Etme Ölçeği Türkçe Formunun Standardize Edilmiş Parametre Tahminleri - ikinci Uygulama

\begin{tabular}{lcccc}
\hline Maddeler & Standardize Edilmiş Faktör Yükleri & $\mathbf{S H}$ & $\mathbf{t}$ & $\mathbf{R}^{\mathbf{2}}$ \\
\hline Madde 1 & .84 & .03 & 24.67 & .71 \\
Madde 2 & .47 & .06 & 7.24 & .22 \\
Madde 3 & .61 & .06 & 10.88 & .37 \\
Madde 4 & .68 & .05 & 14.60 & .46 \\
Madde 5 & .40 & .07 & 6.14 & .16 \\
Madde 6 & .79 & .04 & 21.87 & .62 \\
Madde 7 & .43 & .06 & 7.34 & .18 \\
Madde 8 & .53 & .06 & 9.37 & .28 \\
Madde 9 & .22 & .07 & 3.37 & .05 \\
Madde 10 & .84 & .04 & 23.03 & .71 \\
Madde 11 & .56 & .05 & 10.77 & .31 \\
\hline Madde 12 & .77 & .04 & 20.73 & .60 \\
\hline
\end{tabular}

Not. Tüm t değerleri manidardır $(p<.001)$.

TBOTEÖ’nün Türkçe Formunun Güvenirlik Çalışmalarına iliş̧kin Bulgular

Birinci uygulama sonucunda, ölçeğin iç-tutarlık güvenirlik katsayısı Kuder-Richardson 20 yöntemi ile hesaplanmış ve tüm ölçek için .83 değerine ulaşılmıştır. Bu değerin, Burger'in (1995) geliştirme çalışmasında elde ettiği değerlere (.73 ve .70) göre daha iyi olduğu gözlenmiştir.

İkinci uygulamada elde edilen verinin güvenirliği ise Kuder-Richardson 20 ve testi yarılama yöntemleri ile hesaplanmıştır. Geçerlik ve güvenirlik çalışmaları ölçüme özgü olduğu için ikinci grup veri setin üzerinde de bu hesaplamaların yapılma ihtiyacı hissedilmiştir. Ölçeğin iç-tutarlık güvenirlik katsayısı Kuder-Richardson 20 yöntemi ile hesaplanmış, tüm ölçek için .77 değeri elde edilmiştir. Ayrıca ölçüme ilişkin testi yarılama güvenirlik katsayısı da hesaplanmış ve $r=$ $.65(p<.01)$ değeri elde edilmiştir.

\section{Sonuç ve Öneriler}

Bu çalışmada, Burger (1995) tarafindan geliştirilmiş olan Tek Başına Olmayı Tercih Etme Ölçeği Türkçeye çevrilmiş ve Türkçe formun üniversite öğrencilerinden elde edilen veri setinin geçerlik ve güvenirliğine ilişkin kanıtlar elde edilmiştir. Illk olarak, iki farklı katılımcı grup verisi üzerinde yürütülen yapı geçerliği çalışmaları, ölçeğin Türkçe Formunun faktör yapısının, orijinal ölçek çalışmasında elde edilen tek faktörlü yapıyla tutarlılık gösterdiğini ortaya koymaktadır. Diğer ülkelerde yapılan uyarlama çalışmalarında da, benzer şekilde tek faktörlü yapının ortaya konulduğu görülmektedir. Örneğin; Testa, Rohde ve Luciano (2011) tarafindan Brezilyalı bir grup üniversite öğrencisi üzerinde yapılan uyarlama çalışmasında, ölçeğin tek faktörlü bir yapıya sahip olduğu tespit edilmiş̧ir. Ayrıca iki katılımcı grup verisi üzerinde yapılan güvenirlik çalışmaları da, ölçeğin Türkçe Formunun güvenirlik katsayılarının orijinal çalışmada elde edilen güvenirlik 
katsayılarına göre daha iyi düzeyde olduğunu göstermektedir. Ölçeğin diğer ülkelerdeki uyarlama çalışmalarında elde edilen iç-tutarlık güvenirlik katsayıları da, bu çalışmada elde edilen güvenirlik katsayılarına yakın değerlerdir. Örneğin; Brezilya'daki uyarlama çalışmasında (Testa, Rohde \& Luciano, 2011) elde edilen iç-tutarlık güvenirlik katsayısı .76 iken, Hollanda'daki uyarlama çalışmasında (Staak, 2016) elde edilen değer .70'tir. Bu sonuçlar, ölçeğin faktör yapısının çeşitli kültürlerde elde edilen veri setleri üzerinde benzer bir yapıya ve yeterli güvenirliğe sahip olduğunu göstermektedir.

Bireylerin tek başına olmaya ne denli eğilimli olduğunu belirlemeye yarayan bu ölçek, Türkiye'deki araştırmacı ve uygulamacılara birçok yönden katkı sağlayabilir. İnsanların git gide daha yoğunlaşan ve ağırlaşan hayatlarında tek başına olma gibi temel bir durumu ne derece seçtikleri ya da seçebildikleri araştırmacılar tarafindan bu ölçme aracı ile ortaya konulabilir. Devamında ise, tek başına olmayı farklı düzeylerde seçen insanların ne derece yalnızlık, sosyal kaygı, mutluluk, iyi oluş gibi durumları tecrübe ettikleri araştrılabilir. Bu sayede tek başına olma deneyiminin doğası ve diğer değişkenlerle nasıl bir etkileşim içinde olduğu kuramsal görüşlerin yanında araştrmalarla da bilimsel olarak ortaya konulabilir. Tek Başına Olmayı Tercih Etme Ölçeği'nin uyarlanmasının eğitim ortamlarında çalışan uzmanlar (psikolojik danışmanlar, psikologlar gibi) açısından bazı yararları bulunmaktadır. Alanyazında, tek başına olma deneyiminin eğitim ortamlarında öğrencilerin yaratıcılığıı, kendilerini tanımalarını, huzur ve rahatlama duygularını geliştirebileceğine değinen çalışmalar mevcuttur (Chan, 2016; Galanaki, 2005; Stern, 2016). Bu görüşlerin doğruluk derecesi, yani tek başına olmayı tercih eden bireylerin bu deneyimden ne şekilde yararlanabildikleri bu ölçme aracı ile araştrılabilir.

Bu çalışmada elde edilen geçerlik ve güvenirlik kanıtları her ne kadar yeterli düzeyde olsa da, araştırmanın katılımcıları uygun örnekleme yöntemi ile seçildiği için araştırma sonuçlarının genellenebilirliği açısından bir sınırlılık bulunmaktadır. Bu çalışmadaki veriler Ankara'daki merkez bir üniversitede okuyan öğrenciler üzerinden toplandığı için, geçerlik ve güvenirlik çalışmalarının farklı örneklemler ya da ölçümler üzerinde tekrar incelenmesi alanyazına katkı sağlayacaktır. Bu çalışmalarda ölçekle ilgili farklı geçerlik (örn. benzer ölçek geçerliği, ayırma geçerliği, yordama geçerliği) ve güvenirlik yöntemlerine (test-tekrar test güvenirliği) yer verilebilir. Sonraki çalışmalarda, tek başına olma durumunun kendisiyle benzerlik gösteren, ancak büyük bir oranda farklılaşan yalnızlık, sosyal geri çekilme, sosyal izolasyon, toplumdan uzaklaştırma gibi kavramlarla ilişkisinin araştırılıp, geçerlik kanıtları sunulması yararlı olacaktır.

\section{Kaynakça}

Barbour, J. D. (2014). A view from religious studies. In R. J. Coplan ve J. C. Bowker (Eds.), The Handbook of solitude (pp. 557-571). West Sussex: Wiley Blackwell.

Browne, M. W., \& Cudeck, R. (1993). Alternative ways of assessing model fit. In K. A. Bollen \& J. S. Long (Eds.), Testing structural equation models (pp. 136-162). Newbury Park, CA: Sage.

Bruneau, T. (2011). An ecology of natural mindlessness: Solitude, silence and transcendental consciousness. Explorations in Media Ecology, 10, 55-73. doi:10.1386/eme.10.1-2.55_1

Burger, J. M. (1995). Individual differences in preference for solitude. Journal of Research in Personality, 29(1), 85-108. doi:10.1006/jrpe.1995.1005

Cady, J. (2010). Positive solitude: An examination of individuals who spend frequent time alone (Unpublished master's thesis). The University of British Columbia, Canada.

Chan, L. (2016). Rethinking solitude in schools: How silence and solitude can benefit students and enhance creativity (Unpublished master's thesis). University of Toronto, Canada.

Costache, A. (2013). On solitude and loneliness in hermeneutical philosophy. META: Research in Hermeneutics, Phenomenology, and Practical Philosophy, 1, 130-149. Received from http://www.metajournal.org/

Cramer, K. M., \& Lake, R. P. (1998). The Preference for Solitude Scale: Psychometric properties and factor structure. Personality and Individual Differences, 24(2), 193-199. doi:10.1016/S0191-8869(97)00167-0

Driskell, J. E., Salas, E., \& Hughes, S. (2010). Collective orientation and team performance: Development of an individual differences measure. Human Factors: The Journal of the Human Factors and Ergonomics Society, 52(2), 316-328. doi:10.1177/0018720809359522

Fromm, E. H. (1941). Escape from freedom. New York; NY: Henry Holt.

Galanaki, E. (2004). Are children able to distinguish among the concepts of aloneness, loneliness, and solitude? International Journal of Behavioral Development, 28(5), 435-443. doi:10.1080/01650250444000153

Galanaki, E. (2005). Solitude in the school: A neglected facet of children's development and education. Childhood Education, 81(3), 128-132. doi:10.1080/00094056.2005.10522255

Hair, J. F., Black, W. C., Babin, B. J., \& Anderson, R. E. (2010). Multivariate data analysis (7th ed.): Pearson Company.

Hills, P., \& Argyle, M. (2001). Happiness, introversion-extraversion and happy introverts. Personality and Individual Differences, 30(4), 595-608. doi:10.1016/S0191-8869(00)00058-1 
Hu, L. T., \& Bentler, P. M. (1999). Cutoff criteria for fit indexes in covariance structure analysis: Conventional criteria versus new alternatives. Structural Equation Modeling: A Multidisciplinary Journal, 6(1), 1-55. doi:10.1080/10705519909540118

Joreskog, K. G., \& Sorbom, D. (2004). LISREL 8.71. Lincolnwood, IL: Scientific Software International Inc.

Kline, R. B. (1998). Principles and practice of structural equation modeling. New York: The Guilford Press.

Knafo, D. (2012). Alone together: Solitude and the creative encounter in art and psychoanalysis. Psychoanalytic Dialogues, 22(1), 54-71. doi:10.1080/10481885.2012.646605

Larson, R., \& Csikszentmihayli, M. (1978). Experiential correlates of time alone in adolescence. Journal of Personality, 46(4), 677-693. doi:10.1111/j.1467-6494.1978.tb00191.x

Larson, R. W. (1990). The solitary side of life: An examination of the time people spend alone from childhood to old age. Developmental Review, 10, 155-183. doi:10.1016/0273-2297(90)90008-R

Liang, J., \& Leung, L. (2018). Comparing smartphone addiction: The prevalence, predictors, and negative consequences in Hong Kong and Mainland China. The Journal of Social Media in Society, 7(2), 297-322. Retrieved from http://www.thejsms.org/ index.php/TSMRI/article/view/431/205

Long, C. R. (2000). A comparison of positive and negative episodes of solitude (Unpublished master's thesis). Massachusetts Amherst University, USA.

Long, C. R., \& Averill, J. R. (2003). Solitude: An exploration of benefits of being alone. Journal for the Theory of Social Behaviour, 33(1), 21-44. doi:10.1111/1468-5914.00204

Long, C. R., Seburn, M., Averill, J. R., \& More, T. A. (2003). Solitude experiences: Varieties, settings, and individual differences. Personality and Social Psychology Bulletin, 29(5), 578-583. doi:10.1177/0146167203251535

Maslow, A. (1970). Motivation and personality. New York: Harper \& Row.

Nance, W. Z., \& Mays, M. (2013, March). Exploring the role of time alone in modern culture. Paper presented at the American Counseling Association Conference, Cincinnati, $\mathrm{OH}$.

Perlman, D., \& Peplau, L. A. (1981). Toward a social psychology of loneliness. Personal Relationships, 3, 31-56. Retrieved from http://www.peplaulab.ucla.edu/

Rokach, A. (2011). From loneliness to belonging: A review. Psychology Journal, 8, 70-81. Retrieved from http://resolver.ebscohost.com/

Russell, D., Peplau, L. A., \& Cutrona, C. E. (1980). The Revised UCLA Loneliness Scale: Concurrent and discriminant validity evidence. Journal of Personality and Social Psychology, 39(3), 472-480. doi:10.1037/0022-3514.39.3.472

Russell, D., Peplau, L. A., \& Ferguson, M. L. (1978). Developing a measure of loneliness. Journal of Personality Assessment, 42(3), 290-294. doi:10.1207/s15327752jpa4203_11

Staak, A. van der (2016). The cohesion between living situation, loneliness, depressive symptoms, the preference for solitude and emotional dampening in a Dutch sample of older adults (Unpublished master's thesis). Utrecht University, Nederlands.

Stern, J. (2016). Solitude and spirituality in schooling: The alternative at the heart of the school. In H. E. Lees ve N. Noddings (Eds.), The palgrave international handbook of alternative education (pp. 431-445). London: Palgrave Macmillan.

Storr, A. (1988). Solitude: A return to the self. New York: Ballantine Books.

Tabachnick, B. G., \& Fidell, L. S. (2013). Using multivariate statistics ( $6^{\text {th }}$ ed.). Boston, MA: Pearson

Testa, M. G., Rohde, L. R., \& Luciano, E. M. (2011). As preferências de estudantes universitários por contato social. Administração: Ensino e Pesquisa, 12(1), 93-118. Retrieved from http://repositorio.pucrs.br/

Ullman, J. B. (2001). Structural equation modeling. In B. G. Tabachnick \& L. S. Fidell (Eds.), Using multivariate statistics (Fourth ed.). Needham Heights, MA: Allyn \& Bacon.

Wang, Y. (2006). Culture and solitude: Meaning and significance of being alone (Unpublished master's thesis). Massachusetts Amherst University, USA.

Winnicot, D. W. (1958). The capacity to be alone. In D. W. Winnicot (Ed.), The maturational processes and the facilitating environment (pp. 24-36). New York: International Universities Press.

Winnicot, D. W. (1965). The maturational process and the facilitating environment: Studies in the theory of emotional development. New York: International Universities Press. 